\section{Radio-telephone Link from Scotland to Ireland}

The experiments of the Post Office engineers with ultra-short wave radio-telephony links across the Bristol Channel have already been mentioned in these columns. During December, transmitting and receiving stations were installed in Scotland and Ireland with the view of providing in the New Year six radio telephone channels in the wave-length range 4-5 metres. The Times reports that shortly before Christmas, however, the ordinary submarine telephone cables broke down, and three of the new radio links were brought into operation by the postal authorities in order to maintain the telephone traffic between the two countries. The positions of the wireless stations are at Enoch Hill, near Portpatrick, on the Scottish side, and Ballywater, near Belfast, on the Irish side. The sites were specially chosen on account of their height and freedom from obstruction, and at both places there are ample facilities for extension. This wireless link has already dealt successfully with a number of telephone calls from all parts of Great Britain to Ireland, and the callers have, without knowing it, been taking part in an important experiment in wireless telephony. An antenna array is used at each station to concentrate the radiation into a beam in the desired direction, and the telephone communication may thus be regarded as secret for most practical purposes. The development is of particular interest to Scotland, because of the possibility of applying the system to link up many districts in the Western Isles that are at present isolated so far as telephone communication is concerned. The laying of submarine cables is very expensive, and it is likely that the radio link will provide the means of linking up many districts on the west coast at very much lower cost.

\section{A Radio Beacon at Southampton}

THE coasts of the British Isles are already equipped with a number of fixed radio beacons, which frequently and automatically emit characteristic signals for the use of ships fitted with radio direction-finders. Such beacons are found to be of great assistance to marine navigation, particularly during foggy or stormy weather. According to the Southampton correspondent of the Times, an agreement has now been reached between Trinity House, the Cunard White Star line and the Southampton Harbour Board, as a result of which a radio beacon will be installed on the Nab Tower for the benefit of ships using Southampton Harbour. This tripartite agreement provides for the sharing of the cost of installation and maintenance of the beacon, which, however, will be owned and operated by Trinity House, the authority to which all similar fixed beacons in Great Britain belong. The decision to carry out this new installation is particularly opportune, as the Compagnie Générale Transatlantique has just decided that, in future, all its westbound steamers from France to America will call at Southampton.

\section{British Empire Air Mails}

Sir PhIxIP Sassoon, speaking in the House of Commons recently, outlined fresh proposals for the development of Empire air communications. These, he stated, represent His Majesty's Government's considered scheme, but are necessarily provisional until the other Empire Governments concerned have examined them. There are three main features: an improvement on present time schedules, an increase of frequency of service, and the automatic transfer of all first-class mail to air transport. The new proposals envisage a time of seven days to Australia and four days to the Cape, with proportionate times for intermediate places. This will be made possible by progressive development of ground organisation to enable night flying to operate over the whole of the routes. There will be possibly five services a week to India, three to Singapore and East Africa, and two to Australia and South Africa respectively. It is hoped to keep the charge the same as the present Empire rate of $1 \frac{1}{2} d$. by reducing the permissible weight to half an ounce. It is suggested that correspondence covering eight sides of a special light paper can be sent within that limit. The new services will cater for passengers as well as mail. The completion of the negotiations, provision of the necessary fleet, ground organisation, etc., will take at least two years, and the Postmaster-General has stated that there is little possibility of the introduction of the new postal rate before 1937 .

\section{Isoth Anniversary of The Times}

ON January 1, 1785, The Daily Universal Register began publication as a modest news sheet at the price of $2 \frac{1}{2} d$. The journal was intended, in the first place, as much to advertise the Logographic Press, set up by John Walter near Printing House Court or Yard, Blackfriars, as to function as a newspaper. The title of the paper soon became The Times, which now celebrates its one hundred and fiftieth anniversary by the publication of a supplement of thirty pages, in which the history and activities of the paper are surveyed. During the past century and a half, both the technique of printing and the art of news gathering and presentation have been revolutionised, largely through the progress of scientific developments. The Times was printed at first on hand-presses, which turned out about 250 copies an hour. On November 29, 1814, the steam printing machine developed by Friedrich Koenig (1774-1833), was used, which immediately increased the output to more than a thousand copies an hour. Since then progress has been rapid and speeds of 40,000 copies an hour are now in use. On the side of news gathering, progress has been even more spectacular. In the early days, foreign news came mostly from foreign journals. Nowadays, all the channels for rapid communication opened up by science are utilised to the utmost. Correspondents are appointed in the principal cities throughout the world or sent specially to places of interest, from which the latest news and reports are transmitted, by telegraph and radio, in word and 